\title{
CONSEQUÊNCIAS DA MATERNIDADE NA ADOLESCÊNCIA
}

Maria de Fátima Cordeiro Trajano ${ }^{1}$, Glauberto da Silva Quirino², Gleice Adriana Araújo Gonçalves ${ }^{3}$

RESUMO: Estudo descritivo, com abordagem qualitativa, objetivou compreender as mudanças ocorridas após a maternidade na adolescência. As 17 primíparas adolescentes que participaram da pesquisa foram selecionadas com base nos critérios de inclusão e exclusão, em um serviço de referência no Município de Barbalha-Ceará, e a coleta dos dados se deu por meio de entrevista semiestruturada durante visitas domiciliares no período de junho a outubro de 2011. A técnica de análise de conteúdo contribuiu como método de organização e análise dos dados e da qual emergiu a categoria Consequências da maternidade na adolescência e as subcategorias de análise Consequências sociais da maternidade, Percepção negativa sobre a autoimagem, Consequencias comportamentais da maternidade e Preocupação/insegurança com a contracepção. O estudo possibilitou reforçar outros achados sobre a temática, desvelando aspectos importantes e suas repercussões na vida das adolescentes.

PALAVRAS-CHAVE: Saúde do adolescente; Gravidez na adolescência; Reprodução; Enfermagem.

\section{CONSEQUENCES OF MATERNITY IN ADOLESCENCE}

ABSTRACT: This descriptive study with a qualitative approach aimed to investigate the changes occurring after maternity in adolescence. The 17 adolescent primiparas who participated in the research were selected based on criteria of inclusion and exclusion, in a referral service in the municipality of Barbalha in the state of Ceará. Data collection was through semi-structured interviews during home visits in the period June - October 2011. The technique of content analysis was used for organizing and analyzing the data, from which the following category emerged: Consequences of maternity in adolescence, along with the sub-categories Social consequences of maternity, negative perception of self-image, maternity's behavioral consequences and Worry/insecurity with contraception. The study supported other findings on this issue, revealing important aspects and their repercussions in the adolescents' lives.

KEYWORDS: Adolescent health; Pregnancy in adolescence; Reproduction; Nursing.

\section{CONSECUENCIAS DE LA MATERNIDAD EN LA ADOLESCENCIA}

RESUMEN: Estudio descriptivo, con abordaje cualitativo, cuya finalidad fue comprender los cambios que vienen con la maternidad en la adolescencia. Las 17 primíparas adolescentes que participaron de la investigación fueron seleccionadas por medio de los criterios de inclusión y exclusión, en un servicio de referencia en municipio de Barbalha, Ceará. Los datos fueron recogidos por medio de entrevista semiestructurada durante visitas domiciliares en el periodo de junio a octubre de 2011. La técnica de análisis de contenido contribuyó como método de organización y análisis de los datos. De ella emergió la categoría Consecuencias de la maternidad en la adolescencia y las subcategorías de análisis Consecuencias sociales de la maternidad, Percepción negativa sobre la autoimagen, Consecuencias comportamentales de la maternidad y Preocupación/inseguridad con la contracepción. El estudio posibilitó destacar otros aspectos de la temática, desvelando factores importantes y sus repercusiones en la vida de las adolescentes.

PALABRAS-CLAVES: Salud del adolescente; Gravidez en la adolescencia; Reproducción; Enfermería.

${ }^{1}$ Enfermeira. Mestranda em Saúde da Criança e do Adolescente pela Universidade Federal do Pernambuco - UFPE. Bolsista CNPq. ${ }^{2}$ Enfermeiro. Doutor em Educação em Ciências: Química da Vida e Saúde. Professor do Curso de Graduação em Enfermagem da Universidade Regional do Cariri - URCA. Membro do Grupo de Pesquisa em Saúde Coletiva - GRUPESC.

${ }^{3}$ Enfermeira. Mestre em Enfermagem. Professora do Curso de Graduação em Enfermagem da URCA. Membro do GRUPESC.

Autor correspondente:

Maria de Fátima Cordeiro Trajano

Universidade Federal do Pernambuco

Rua Adelino Frutuoso, 160 - 50721-200 -Recife-PE-Brasil

E-mail: enffatimact@gmail.com
Recebido: 13/02/2012

Aprovado: 02/07/2012

Cogitare Enferm. 2012 Jul/Set; 17(3):430-6 


\section{INTRODUÇÃO}

A adolescência, período circunscrito dos 10 aos 19 anos, compreendendo a adolescência inicial de 10 a 14 anos e a final, de 15 a 19 anos, contempla uma etapa evolutiva na vida do ser humano ${ }^{(1)}$. Essa fase é caracterizada por um conjunto de transformações sociopsicológicas e anátomo-metabólicas, a qual permite que o indivíduo seja exposto a um modelo de vida até então desconhecido. Porém, ao mesmo tempo, estabelece padrões comportamentais e sonhos que permearão toda a vida. $\mathrm{O}$ adolescente procura assumir sua identidade, afastando-se dos padrões estabelecidos pelos pais, ao perpassar por mudanças na percepção acerca do corpo, do despertar para sexualidade e dos novos valores de vida(2).

Muitas vezes, em uma fase considerada como elemento de transição para um novo mundo, o jovem realiza descobertas e tem novos anseios, ocorrem alterações físicas, psíquicas e sociais, maturação no nível do intelecto, cujo adolescente procura entender quem é e qual o seu real papel na sociedade ${ }^{(3)}$. É, nesse período, que, geralmente, os jovens iniciam suas primeiras experiências sexuais, começando cada vez mais cedo, e nem sempre de forma racional, quanto às consequências, entre elas, a gravidez. Por isso, o apoio aos adolescentes por parte da família, da escola e dos serviços de saúde é de suma importância para que possam tolerar melhor as alterações desta fase não se sentindo tão vulneráveis ${ }^{(4)}$.

Em um contexto em que se supõe que a adolescente não deveria engravidar, já que tem possibilidades de ascensão educacional, econômica e pessoal, as transformações na vivência da sexualidade têm propiciado a ocorrência da gravidez cada vez mais precoce. As razões pelas quais as adolescentes engravidam precocemente são múltiplas, podendo ser de ordem socioeconômica, familiar ou pessoal ${ }^{(4)}$. Entre os fatores de risco envolvidos na ocorrência da gravidez na adolescência, cita-se o início da puberdade, que vem acontecendo cada vez mais cedo, além da iniciação sexual ser cada vez mais precoce, a insuficiente orientação sexual na escola, nos serviços de saúde e, principalmente, na família ${ }^{(2,5)}$.

A primiparidade precoce acarreta várias repercussões que vão desde o caráter físico e psicológico até o socioeconômico e educacional. A adolescente defronta-se com as alterações corporais da própria fase, juntamente com as da gestação. Estas afetam sua percepção acerca da autoimagem e autoestima, que se justapõe à insegurança quanto à maternidade e responsabilidade em relação ao filho. Assim, as alterações comportamentais e familiares interferem na continuidade dos estudos, nas atividades próprias da idade que eram realizadas antes da gestação e na convivência social. Tem-se como pressuposto que a gravidez na adolescência é vivida de múltiplas formas e que os contextos sociais definem universos de possibilidades e de significações diferentes entre os jovens de distintas classes sociais ${ }^{(6)}$.

A partir desses pressupostos, considerando que é fundamental a apreensão do fenômeno e das repercussões da gravidez na adolescência, objetivou-se compreender as mudanças ocorridas após a maternidade na adolescência.

Tal pesquisa traz consigo a relevância de fornecer subsídios para que os trabalhadores da saúde, especialmente os enfermeiros, principal agente da promoção da saúde no contexto da Equipe de Saúde da Família, conheçam melhor a problemática, viabilizando outro olhar sobre as ações destinadas a esse público, bem como ajudando a adolescente a adaptar-se às transformações que a maternidade impõe. Esses elementos são fundamentais para o respeito à individualidade $\mathrm{e}$ cuidado centrado no sujeito, além de instrumentalizar os agentes promotores de cuidados e direcionar suas práxis e políticas.

\section{MÉTODO}

Trata-se de uma pesquisa de natureza descritiva, com abordagem qualitativa, uma vez que houve a preocupação com a interpretação dos significados construídos pelas atrizes sociais, respondendo a particularidades que não podem ser quantificadas, fundamentando-se na tentativa de compreender um problema na perspectiva das adolescentes.

A pesquisa foi realizada em um serviço de atenção secundária, destinado a tratar da saúde maternoinfantil, situado no Município de Barbalha-CE; este apresenta uma área de $599 \mathrm{Km}^{2}$ com uma população de 55.373 habitantes $^{(7)}$, a escolha do local deu-se por se tratar de um serviço referência que atendia um grande número de mães adolescentes. A coleta de dados ocorreu entre junho e outubro de 2011, foi realizada em dois momentos e a saturação teórica dos dados foi utilizada como critério para seu encerramento.

No primeiro momento, após a anuência da Secretária de Saúde e da Coordenadora do Centro de Saúde Materno-infantil, foram selecionados os prontuários de mães adolescentes que foram atendidas nos serviços 
de aleitamento materno e/ou puericultura do Centro de Saúde, para que se pudesse ter acesso aos endereços das participantes. No segundo momento, iniciaram-se visitas aos endereços registrados nos prontuários, as quais se repetiram conforme a necessidade de aprimoramento dos dados.

Foram selecionadas para compor a pesquisa 17 mulheres que preencheram os seguintes critérios de inclusão: estar na faixa etária da adolescência final, dos 15 aos 19 anos, por acreditar que houvesse maior facilidade de encontrar primíparas adolescentes nesta faixa etária e por concentrar-se fora do risco obstétrico; ser primípara; ser atendida no serviço de referência do Centro de Saúde Materno-Infantil de Barbalha-CE, no serviço de puericultura e/ou aleitamento materno e aceitar gravar a entrevista.

Foram critérios de exclusão: ser adolescente portadora de transtorno mental; e residir em área de difícil acesso para realização da visita pela pesquisadora.

O instrumento de coleta de dados consistiu em um roteiro de entrevista semiestruturada, contendo as seguintes variáveis: estado civil, idade, ocupação, renda familiar, escolaridade, situação escolar atual, ocorrência da primeira menstruação e ocorrência da primeira relação sexual, as questões abertas foram: quais as orientações recebidas sobre os métodos contraceptivos antes da gravidez; em que contexto esta ocorreu; quais as alterações físicas e emocionais percebidas após a gestação; e como se dava o exercício da sexualidade após a maternidade.

Para exploração das falas, a partir das entrevistas, foi utilizada a técnica de análise de conteúdo categorial temática para organização dos dados, esse tipo de análise organiza-se em: pré-análise, exploração do material e tratamento dos resultados, a inferência e a interpretação ${ }^{(8)}$.

A pesquisa obedeceu a todas as recomendações formais da Resolução 196/96, do Conselho Nacional de Saúde do Ministério da Saúde ${ }^{(9)}$, referente a estudos com seres humanos. A decisão de participar, ou não, da pesquisa foi respeitada, bem como garantido seu anonimato, através da utilização do nome de flores, o que garantiu a privacidade de todas as participantes da pesquisa. As adolescentes foram informadas acerca do objetivo do trabalho, da relevância, uma vez que foram garantidas a beneficência, não maleficência, justiça e autonomia através da assinatura do TCLE pelos representantes legais para as adolescentes que não possuíam a maior idade. Este estudo foi submetido ao Comitê de Ética em Pesquisa da Universidade Regional do Cariri, tendo sido aprovado sob parecer número 49/2010.

\section{RESULTADOS}

Entre as 17 adolescentes do estudo, a faixa etária se concentrou no limite superior da adolescência - 19 anos, com média de idade de 17,35 anos.

Apenas duas jovens não tinham parceiros, as demais estavam casadas ou viviam em união estável. Duas adolescentes trabalhavam; os motivos citados pela maioria como causa para a impossibilidade de trabalhar foram os cuidados demandados pelo filho e as responsabilidades com os deveres domésticos. Quanto à renda familiar, 16 adolescentes contavam com renda mensal de até dois salários mínimos. Apenas uma continuou estudando após a descoberta da gravidez. Quanto à menarca, a menor idade constatada de sua ocorrência foi aos 9 anos e a maior aos 14 anos, sendo a média de 11,89 anos. No tocante à iniciação sexual, a idade variou de 12 a 19 anos, com média de 14,82 anos. A gravidez não foi planejada para 12 adolescentes.

A categoria Consequências da maternidade na adolescência foi construída a partir de 366 unidades de registro que geraram quatro subcategorias. Consequências sociais da maternidade foi a mais frequente com 158 unidades de registro, seguida pela Percepção negativa da autoimagem com 97, As consequências comportamentais da maternidade com 57 e Preocupação/insegurança com a contracepção com 54.

\section{Consequências sociais da maternidade}

As adolescentes relataram as mudanças sociais decorrentes da maternidade. Expressaram os sentimentos relacionados à perda de liberdade com os cuidados demandados pelo filho, o ganho de responsabilidade relacionada à maternidade e a evasão escolar:

Antes eu tinha tempo prá mim, prá me arrumar, eu trabalhava, às vezes eu saia, eu gostava de conversar com as minhas amigas, tudo eu curtia um pouco. Agora é só ele, não tenho tempo de me arrumar, de sair, eu evito sair, porque sei que vai dar trabalho. (Acácia)

Parei de estudar por causa do tempo, tenho que cuidar do menino e da casa, não tem com quem ele ficar, o tempo fica muito corrido e puxado. (Jasmim)

Agora tenho responsabilidade, coisa que não tinha, 
antes era só festa e vida boa, agora é roupa pra lavar, casa para cuidar, menino prá banhar, dar comida, botar prá dormir. (Tulipa)

Percebeu-se que a maternidade trouxe diversas consequências sociais para as mães adolescentes deste estudo, entre elas, destaca-se a atribuição da responsabilidade, diretamente relacionada à chegada do filho, uma vez que as adolescentes que antes vivenciavam a plenitude da idade com as atividades relacionadas a esta fase e desfrutavam de certa "liberdade", passaram a vivenciar as restrições acarretadas pela maternidade.

Entretanto, as adolescentes perceberam que a maternidade promoveu a aquisição da responsabilidade e isso denota a entrada na vida adulta, mesmo para aquelas em que a gravidez não foi planejada.

Para algumas mães, a impossibilidade de conciliar os estudos com as atividades demandadas pela maternidade e os deveres domésticos resultou na interrupção temporária dos estudos, no entanto não foram citados por elas os prejuízos escolares decorrentes desta interrupção.

\section{Percepção negativa da autoimagem}

Nesta subcategoria, as adolescentes discorreram sobre as mudanças físicas percebidas em decorrência do processo de gravidez. Expressaram a percepção que tinham sobre a autoimagem após a maternidade:

Meus seios ficaram grande, mais flácido e mole, antes era bem durinho. Eu não sou mais bem feitinha como eu era, magrinha. Eu era bonita, interessante, quando me olho no espelho, me sinto feia, não tenho alegria, não me vejo bonita. (Begônia)

Percebi umas diferenças, engordei mais, aumentei uns quilinhos. Pense como é ruim você se acostumar com um novo corpo, quando lembro como eu era antes dá uma saudade e ao mesmo tempo uma tristeza. (Dália)

As entrevistadas identificaram alterações significativas nas características corporais após o processo de gestação e parto, ainda que a maior parte delas considerasse ter recuperado a forma física em pouco tempo. Algumas descreveram manutenção de práticas de autocuidado, embora com menos tempo para se dedicar a tais tarefas. As mulheres expressaram sentimentos de tristeza e saudosismo relacionado ao corpo que possuíam antes da gravidez, justaposta à resignação com o corpo atual.

\section{Consequências comportamentais da maternidade}

Nesta subcategoria, as adolescentes relataram a respeito das mudanças emocionais e de comportamento que ocorreram devido à maternidade. Declararam os sentimentos relacionados à maternidade, bem como a melhoria a nível pessoal:

Sinto vontade de proteger, não sei nem explicar, agora que sou mãe sinto mais amor, mais felicidade, coisa que eu não sentia na vida. (Begônia)

Um filho muda a vida da gente totalmente, posso te dizer com toda certeza que aprendi a ser mais humana, menos egoísta, antes de ter meu filho eu era muito infantil e egoista, agora sou uma pessoa melhor, além de ter amadurecido bastante. (Hortênsia)

A maternidade para essas mães ocorreu de forma inesperada, o que não resultou em um enfrentamento negativo, pelo contrário, as adolescentes do estudo compreenderam o ato de ser mãe dentro de uma perspectiva de crescimento associado aos fatores positivos trazidos por ela.

Para essas mães, a maternidade foi assimilada como um acontecimento importante em suas vidas, proporcionando-lhes experiência ímpar ao despertar um lado até então não conhecido por elas, a de provedora do cuidado e proteção do filho.

Notou-se, ainda, que através da maternidade, as adolescentes encontraram um sentido maior de viver. $\mathrm{O}$ filho possibilitou vivenciar uma felicidade até então não experimentada, evidenciada pelos termos, "alegria", "amor" e "felicidade".

Observou-se que por mais que a gravidez tenha acontecido precocemente, a maternidade ocorreu de forma tranquila e satisfatória para todas as entrevistadas, uma vez que a necessidade de realizar os cuidados com o filho proporcionou transformação comportamental que favoreceu seu acontecimento.

\section{Preocupação/insegurança com a contracepção}

As adolescentes discursaram sobre a preocupação com a utilização dos métodos contraceptivos, bem como o medo de uma recidiva de gravidez, uma vez que esta preocupação surgiu apenas após a ocorrência da gravidez:

Mais ou menos segura, assim, lógico que agora me preocupo mais em relação a isso, pra não engravidar. 
Depois que a gente tem um filho, se preocupa mais pra não acontecer de novo. Procuro tomar o anticoncepcional bem direitinho. (Acácia)]

Tanto eu como ele, a gente se preocupa pra não acontecer uma gravidez agora, acho que a gente só vai querer esse mesmo. É tanto que antes de engravidar, ele não queria usar a camisinha, agora ele já aceitou mais, mas eu vou começar a tomar a injeção, porque tenho medo de rasgar e aparecer outra criança. (Hortênsia)

Tenho muito medo de engravidar de novo, mesmo tomando todo dia o remédio, penso que vou engravidar, me acho tão sem experiência em relação a essas coisas, não tenho um pingo de segurança. (Rosa)

A iniciação sexual dessas jovens ocorreu de forma desprotegida e desorientada. A gravidez aconteceu para a maioria dessas adolescentes de forma não planejada, em que seu acontecimento não era esperado e, na maioria das vezes, não havia uma consciência sobre tal possibilidade.

Observa-se, através dos discursos, que após a ocorrência da gravidez, essas adolescentes passaram a se preocupar com a questão reprodutiva, para aquelas que engravidaram sem planejamento, o medo com a probabilidade de uma incorreção no método contraceptivo desencadeou insegurança e receio quanto à possibilidade de engravidarem novamente. Contudo, para aquelas que planejaram a gravidez, não se evidenciou esse medo quanto à eficácia do método, apenas preocupação para evitar uma recidiva.

\section{DISCUSSÃO}

Estudo acerca do perfil da gravidez na adolescência em jovens da periferia apresentou uma média de idade entre as adolescentes grávidas de 17 anos, a maioria na faixa de 15 aos 19 anos $^{(10)}$. Uma pesquisa realizada na Paraíba constatou que a maioria das puérperas adolescentes entrevistadas encontrava-se casada ou vivia com companheiro ${ }^{(11)}$.

As primíparas adolescentes desta pesquisa possuíam baixa renda, o que não se diferencia da literatura relacionada à questão socioeconômica associada às mulheres que vivenciam a gravidez na adolescência ${ }^{(12)}$.

Deve-se considerar que a média de idade da menarca vem apresentando tendência à queda, diminuindo cerca de quatro meses a cada década, encontrando-se atualmente na faixa dos 11 a $12 \operatorname{anos}^{(13)}$. Quanto mais cedo ocorrer a menarca e a sexarca, maiores as chances de a adolescente engravidar devido à carência de métodos contraceptivos, pela falta de poder de compra, pelo receio quanto à busca do serviço de saúde e desconhecimento de práticas preventivas ${ }^{(2)}$. Em estudo realizado em Mato Grosso sobre as práticas sexuais de adolescentes, houve associação positiva entre renda familiar e uso de método contraceptivo entre as adolescentes pesquisadas, portanto a baixa renda das adolescentes esteve associada a não utilização de um método contraceptivo ${ }^{(14)}$.

As alterações que ocorrem na rotina das jovens mães incidem principalmente em dois segmentos: a impossibilidade de conciliar os estudos com as atividades demandadas pela maternidade e a perda da liberdade relacionada ao convívio social, corroborando com o estudo realizado em cidades pobres paulistas que evidenciou a privação da liberdade e abandono escolar entre as adolescentes que vivenciaram a maternida$\mathrm{de}^{(15)}$. Isso decorre do fato de a maternidade exigir a assunção de novas responsabilidades, o que provoca a diminuição na participação em atividades recreativas e de lazer, além de limitar o convívio social entre as adolescentes $^{(16)}$.

Nesse sentido, as dificuldades e impedimentos incidem mais precipuamente sobre a trajetória escolar que se torna agravada pela condição de indisponibilidade causada pela necessidade de cuidado dos filhos, principalmente, para aquelas mães que não têm com quem os deixar ${ }^{(15)}$.

Vale ressaltar que a não retomada aos estudos pelas adolescentes pode dificultar a inserção no mercado de trabalho e como consequência diminuir as chances de autonomia econômica em relação à família e ao cônjuge, bem como causar prejuízos quanto à possibilidade de proporcionar melhores condições de cuidado com o filho.

Para além das consequências sociais, as mães adolescentes apresentaram alteração na autoestima devido às modificações corporais resultantes do processo gravídico e da amamentação. Estas alterações, decorrentes da gravidez, são motivos de preocupação para algumas jovens, pois após o nascimento do filho, uma das primeiras conclusões que a mãe tem é que seu corpo já não é mais o mesmo de antes, surgindo incômodo e insatisfação ${ }^{(17)}$. Isso tem potencial de gerar dificuldades na percepção da autoimagem, pois incidem sobre esta as mudanças ocorridas no corpo e as transformações estéticas decorrentes da maternidade ${ }^{(18)}$. 
Diante do turbilhão de transformações decorrentes da gravidez, adaptar-se ao novo corpo depois do nascimento do filho torna-se um processo difícil que pode ser ao mesmo tempo tolerado, dependendo da forma de enfrentamento da adolescente.

Quanto aos aspectos positivos da maternidade, pode-se afirmar que estes estão relacionados à experiência concreta com a criança, para companhia e como propriedade afetiva disponível, o que promove consequências sociais percebidas como benéficas. Assim, como também encontrado na literatura, evidenciouse que o exercício das funções maternas é possível e tolerável, além de ser, muitas vezes, prazeroso para as mulheres ${ }^{(15)}$.

Em relação à preocupação com a contracepção, infere-se que o conhecimento acerca do ciclo reprodutivo e métodos contraceptivos precários estão interligados nesta configuração. O estudo desvela o pouco cuidado das adolescentes com a temática contraceptiva, o que tem potencial de prejudicar seu empoderamento como determinante no processo de escolha e uso. Pode-se indagar se tal precariedade estaria relacionada à insuficiente informação dada pela baixa (ou fraca) escolaridade das jovens ou, ainda, pelas relações desiguais de gênero ${ }^{(19)}$.

Essa dificuldade em gerenciar os meios contraceptivos parece ser transversal nesse grupo etário, pois, em geral, as adolescentes podem perpassar por dificuldades no uso de métodos contraceptivos, em decorrência do uso inadequado ou dos sintomas colaterais ${ }^{(15)}$.

Isto reforça o quanto é necessário rever as práticas educativas a serem realizadas com adolescentes e a frequência com que devem ser procedidas; além disto, torna-se imprescindível a participação dos educadores e familiares neste processo ${ }^{(20)}$.

As dificuldades de reorganização reprodutiva das jovens que vivenciaram a gravidez precoce promovem a necessidade de um trabalho educativo que viabilize minimizar as dúvidas das adolescentes frente às questões sexuais e reprodutivas, reduzindo os riscos de uma nova gravide ${ }^{(15)}$.

Para as adolescentes deste estudo, a maternidade provocou a necessidade de adequação às mudanças sociais relacionadas à evasão escolar e ao distanciamento das atividades próprias da idade, o que ocasionou a perda de liberdade devido aos cuidados demandados pelo filho, bem como ganho de responsabilidade com as atribuições da função de mãe e cuidadora do lar. Todavia, as jovens compreenderam a maternidade e as mudanças originadas por ela dentro de uma perspectiva de crescimento pessoal.

\section{CONSIDERAÇÕES FINAIS}

As consequências da maternidade incidem mais negativamente sobre os aspectos biológicos e sociais da adolescente. Entretanto, ela gera sentimentos de felicidade e assunção de novos papéis sociais, constituindo um novo status e demarcando uma nova etapa evolutiva na vida das mães. Essa característica é marca expressiva da nossa sociedade que espera e deseja que a experiência da maternidade esteja associada a sentimentos nobres em um contexto de responsabilidade. Dessa forma, em uma estreita associação com a expectativa da performance de gênero esperada para as mulheres que usam o ambiente doméstico como espaço de trabalho e cuidado.

A gravidez na adolescência é um fenômeno que contempla várias interfaces, biológica, cultural e social, sendo assim uma questão de saúde pública. As adolescentes que vivenciam a primiparidade precoce necessitam de atendimento individualizado que priorize as demandas psicossociais durante o acompanhamento do pré-natal e puerpério, para que dessa forma sejam preparadas para as mudanças decorrentes da maternidade.

As ações prestadas pelos profissionais de saúde no atendimento ao adolescente devem possibilitar acompanhamento que realmente possa minimizar dúvidas diante de assuntos tão importantes nessa fase da vida, como a sexualidade e as suas consequências, entre elas a gravidez.

Nesse sentido, a relevância do estudo encontra-se em explorar as vivências das adolescentes após a maternidade, possibilitando um olhar diferenciado quanto à percepção e ao atendimento de saúde da mãe adolescente, pois a partir dessa perspectiva são evidenciados aspectos extremamente importantes para seu bem-estar.

Considerando que o estudo foi realizado com mães que vivenciaram a maternidade no período de até um ano após o nascimento do filho, teve como limitação o não acompanhamento por um período maior da maternidade, portanto não foram analisadas as consequências a longo prazo. Ainda, sugere-se um aprofundamento maior considerando aspectos de classe social e raça/etnia.

\section{REFERÊNCIAS}

1. Organización Mundial de la Salud. La salud de los jóvenes: un reto y una esperanza. Ginebra: OMS; 1995.

2. Ximenes Neto FRG, Dias MSA, Rocha J, Cunha ICKO. Gravidez na adolescência: motivos e percepções de adolescentes. Rev. bras. enferm. 2007;60(3):279-85. 
3. Altmann HA. Sexualidade adolescente como foco de investimento político-social. Educ. rev. 2007;(46):287310.

4. Moreira TMM, Viana DS, Queiroz MVO, Jorge MSB. Conflitos vivenciados pelas adolescentes com a descoberta da gravidez. Rev. Esc. Enferm. USP. 2008;42(2):312-20.

5. Oliveira TP, Carmo APA, Ferreira APS, Assis ILR, Passos XS. Meninas de Luz: uma abordagem da enfermagem na gravidez na adolescência. Rev. Inst. Cienc. Saude. 2009; 27(2):122-7.

6. Aquino EML, Heilborn ML, Knauth D, Bozon M, Almeida MC, Araújo J, et al. Adolescência e reprodução no Brasil: a heterogeneidade dos perfis sociais. Cad. saúde pública. 2003;19(2):377-88.

7. Instituto Brasileiro de Geografia e Estatística (IBGE). Censo 2010. [Internet] 2010. [acesso em $2 \mathrm{fev}$ 2011]. Disponível: http://www.ibge.gov.br/cidadesat/ topwindow.htm?1.

8. Bardin L. Análise de conteúdo. Lisboa: Edições 70; 2009.

9. Ministério da Saúde (BR). Conselho Nacional de Saúde. Diretrizes e normas regulamentadoras de pesquisas envolvendo os seres humanos. Resolução n. 196, de 10 de outubro de 1996. Brasília: Ministério da Saúde; 1996.

10. Chalem E, Mitsuhiro SS, Ferri CP, Barros MCM, Guinsburg R, Laranjeira R. Gravidez na adolescência: perfil sociodemográfico e comportamental de uma população da periferia de São Paulo, Brasil. Cad. saude publica. 2007;23(1):177-86.

11. Meincke SMK, Oliveira MRP, Trigueiro DRSG, Carraro TE, Gondim ETC, Collet N. Perfil socioeconômico e demográfico de puérperas adolescentes. Cogitare enferm. 2011;16(3):486-91.

12. Levandowski DC, Piccinini CA, Lopes RCS. Maternidade adolescente. Estud. psicol. 2008;25(2):251-63.

13. Berlofi LM, Alkmin ELC, Barbieri M, Guazzelli CAF, Araújo FF. Prevenção da reincidência de gravidez em adolescentes: efeitos de um Programa de planejamento familiar. Acta paul. enferm. 2006;19(2):196-200.

14. Bagli DM, Miranda S, Martins, CBG, Matos KF. Questões socioeconômico-familiares associadas à prática sexual de adolescentes: um estudo da capital de Mato Grosso. Cogitare enferm. 2011;16(4):667-74.
15. Monteiro NRO. Perfis de Adolescentes Mães Após Três Anos e Meio do Nascimento do Bebê: Seguimento Longitudinal de Estudo Psicossocial. Interação psicol. 2008;12(2):291-7.

16. Carvalho GM, Merighi MAB, Jesus MCP. Recorrência da parentalidade na adolescência na perspectiva dos sujeitos envolvidos. Texto Contexto Enferm. 2009;18(1):17-24.

17. Belentani LM, Marcon SS, Pelloso SM. Sexualidade de puérperas com bebês de risco. Acta paul. enferm. 2011; 24(1):107-13.

18. Esteves JR, Menandro PR. Trajetórias de vida: Repercussões da maternidade adolescente na biografia de mulheres que viveram tal experiência. Estud. psicol. 2005;10(3):363-70.

19. Cabral CS. Contracepção e gravidez na adolescência na perspectiva de jovens pais de uma comunidade favelada do Rio de Janeiro. Cad. saúde pública. 2003;19(Suppl 2):283-92.

20. Camargo EAI, Ferrari RAP. Adolescentes: conhecimentos sobre sexualidade antes e após a participação em oficinas de prevenção. Ciênc. saude colet. 2009;14(3):937-46. 